\title{
ORIENTAÇÃO PROFISSIONAL SOB O ENFOQUE DA ANÁLISE DO COMPORTAMENTO: AVALIAÇÃO DE UMA EXPERIÊNCIA
}

\author{
BEHAVIORAL APPROACH APPLIED TO CAREER COUNSELING \\ WITH ADOLESCENTS: \\ THE EVALUATION OF AN EXPERIENCE
}

Cynthia Borges de MOURA ${ }^{1}$ Jocelaine Martins da SILVEIRA²

\begin{abstract}
RESUMO
O objetivo deste trabalho foi avaliar uma experiência de atendimento de grupo em Orientação Profissional segundo o enfoque da Análise do Comportamento. Procurou-se avaliar as mudanças ocorridas no comportamento dos adolescentes quanto aos indicadores da escolha profissional. Participaram da intervenção dez adolescentes, de ambos os sexos, com idades entre 15 e 19 anos, alunos do Ensino Médio. O programa constou de nove sessões semanais estruturadas para discussão da problemática vocacional, focalizadas no desenvolvimento de auto-conhecimento e conhecimento das profissões. Antes do início e ao final dos atendimentos foi aplicado um instrumento contendo questões referentes aos indicadores da escolha profissional para levantamento de dados a serem comparados. Os resultados mostraram que 50\% dos adolescentes conseguiram efetivar a escolha profissional e os outros 50\% avançaram quanto aos critérios pessoais de seleção profissional. Estes resultados indicam que o modelo parece efetivo e necessita ser aprimorado para alcançar as necessidades de todos os adolescentes que procuram pelo Programa.
\end{abstract}

Palavras-Chave: Orientação Profissional, Orientação Vocacional, Escolha Profissional, Análise do Comportamento.

\footnotetext{
(1) Universidade Estadual de Londrina.

(2) Universidade Estadual de Londrina.

Endereço para Correspondência: Universidade Estadual de Londrina

Departamento de Psicologia Geral e Análise do Comportamento

Campus Universitário - Caixa Postal 6001 - CEP: 86051-990

E-mail: jsilveira@sercomtel.com.br / cybmoura@uol.com.br - Fone: (043) 371-4227 (com.) ou 339-4016 (res.)
} 


\begin{abstract}
This work aimed at evaluating na experience of group assistance in Career Counseling according to the Behavioral Approach. Attempsts were made to evaluate the changes that took place in the behavior of adolescents regarding the indicators of professional choice. Tem adolescents, both male and female, ranging from 15 to 19 years of age, attending high school participated in the intervention. The orientation program consisted in nine weekly sessions, outlined towards the discussion of the vocational issue. The sessions focused on the development of self-knowledge and the knowledge of the professions. At the beginning and end of the program na instrument with questions about the indicators of professional choice was applied, to collect data for further comparison. The results showed that $50 \%$ of the adolescents managed to make a professional choice, whereas the other 50\% made progress concerning personal criteria for professional decision. The results indicated that the model seems to be effective and needs to be improved to reach the needs of the adolescents that look for the Program's assistance.
\end{abstract}

Key-words: Career Counseling, Vocational Guidance, Professional Choice, Behavioral Analysis.

Este trabalho refere-se a sistematização de um Programa de Orientação Profissional segundo o referencial teórico da Análise do Comportamento. Esta proposta surgiu frente a crescente demanda na área de Orientação Profissional, a necessidade de desenvolvimento de um instrumental adequado para lidar com a complexidade desta problemática e a escassez, ou inexistência, de trabalhos sistematizados que se proponham a investigar o dilema da escolha profissional de forma elaborada, principalmente sob o ponto de vista comportamental.

O presente estudo investigou a efetividade do emprego da Análise Funcional do Comportamento como método que norteou estratégias de intervenção para ajudar adolescentes na escolha profissional. Partiu-se do pressuposto de que a Análise do Comportamento tem importantes contribuições para a área de Orientação Profissional dado seu caráter funcionalista, contextualista e diretivo, podendo realizar análise de contingências direcionada a uma tomada de decisão mais consciente por parte do adolescente.

\section{Delineando um modelo comportamental de Orientação Profissional}

A Análise do Comportamento não possui um modelo estruturado da prática em Orientação Profissional, embora ofereça possibilidade de interpretação da problemática da escolha profissional. Freqüentemente, os analistas do comportamento se esquivam da tarefa de ajudar adolescentes a optar pelas profissões, encaminhando clientes com esta demanda para outros profissionais. Por vezes, realizam trabalhos de orientação profissional sem, no entanto, preocuparem-se em relatar seus procedimentos para a comunidade de clínicos.

Este fato parece ser decorrente da recusa em aderir aos modelos tradicionais de aconselhamento nesta área, o qual tem sido costumeiramente chamado de "Orientação 
Vocacional". Por sua conotação tradicionalmente mentalista, o termo "vocação" pode ter afastado o interesse de Analistas do Comportamento pela problemática, pois dito de outro modo, "descobrir a vocação" implica num engajamento em diversos comportamentos relacionados à escolha profissional.

\section{Analisando comportamentalmente a "vocação"}

Em primeiro lugar, há que se pensar qual o conceito de "vocação" para a Análise do Comportamento. Parece evidente a rejeição do modelo de "vocação" como algo inerente a pessoa, determinado internamente e que precisa apenas ser desvelado ao seu portador. Partindo de uma visão de homem completamente diferente (Skinner, 1974, 1989), a Análise do Comportamento entende "vocação" como uma construção pessoal, ou, como um conjunto complexo de variáveis filo e ontogenéticas que se arranjam de forma única para cada indivíduo. Dito de outra forma, a "vocação" é um conceito socialmente construído, na medida em que existe um conjunto de valores e normas sociais aos quais se espera que as pessoas respondam, adequando suas características a padrões de um dado momento histórico.

Portanto, a "vocação" de uma pessoa é socialmente determinada e implicará numa combinação única de sua história genética, pessoal, familiar e cultural. O arranjo destas variáveis ao longo da vida do indivíduo irá encaminhá-lo para o desenvolvimento de interesses e habilidades que deverão se enquadrar em um conjunto razoavelmente restrito de opções profissionais (Macedo, 1998). Um procedimento de aconselhamento profissional nos moldes comportamentais deve: I) levar o indivíduo a discriminar as variáveis destes diferentes contextos de controle às quais seus comportamentos de escolher e de decidir estão expostos; 2) proporcionar informação relevante sobre as profissões de interesse, discutindo compatibilidades e perspectivas; e 3) aumentar a probabilidade de ocorrência de comportamentos relacionados à escolha e/ou à tomada de decisão.

\section{A decisão como um processo comportamental}

Segundo Skinner (1989) o comportamento de decidir é essencialmente um processo de geração de condições que tornarão um dado curso de ação mais provável que outro. O processo pode ser ilustrado por meio do exemplo de alguém que se diz decidido a passar as férias na praia, ao contar isso aos colegas, a pessoa controla o curso de seu próprio comportamento, reduzindo a probabilidade de mudar de idéia. "Decidir-se" é, para Skinner, antes de tudo, um "processo", o qual está relacionado a uma classe de estímulos, muitas vezes manipulada pela própria pessoa que está se decidindo.

Em suma, a prática de orientação profissional sob o enfoque da análise do comportamento pressupõe a modelagem de classes comportamentais relacionadas à escolha e à decisão que são, em si mesmas "processos". Desse modo, o produto ou o conteúdo da escolha são de menor relevância quando comparados à primazia da aprendizagem de decidir e/ou escolher, que caracteriza o objetivo geral da Orientação Profissional. De acordo com o que foi exposto, o processo de escolha requer o oferecimento de classes de estímulos que se traduzem pelas chamadas "opções profissionais" a serem consideradas.

\section{O Comportamento Verbal na Orientação Profissional}

Tanto quanto a análise do contexto de vida do adolescente, é importante o conhecimento das regras às quais ele responde. "Como o orientando comporta-se 
verbalmente durante as sessões?" Essa pergunta levará o analista do comportamento a 1) identificar pensamentos e sentimentos relativos a escolha profissional; 2) interpretar como os contextos passado e presente do adolescente interferem na tomada de decisão; 3) identificar (para, posteriormente alterar) regras mantenham relações impróprias ou distorcidas com contingências reais que se refiram à escolha profissional. O orientador avalia com os adolescentes a adequação de algumas regras e frequentemente discute com eles regras tais como: "Eu preciso acertar na minha escolha porque ela é definitiva e será irreversível"; "O dano para a minha vida será irreparável, caso eu me engane na escolha", "Se eu optar pela carreira 'certa' eu não encontrarei obstáculos profissionais", as quais impedem a consideração de mudanças nos rumos profissionais caso hajam alterações nas contingências presentes ou futuras.

\section{Contribuições de outras abordagens a compreensão do problema}

Em nossa experiência de Orientação Profissional sob enfoque da Análise do Comportamento temos, por meio de leituras de textos clássicos, buscado informações oriundas da prática tradicional em Orientação Vocacional. Acreditamos que a experiência desses clínicos pode trazer indicações úteis de caracterização da população, bem como de recursos e técnicas de intervenção, que com algumas modificações venham complementar nossa prática. Por exemplo, os modelos psicodinâmicos (Holland, 1971; Roe, 1972; Bohoslavsky, 1977) apontam a importância da inclusão de metas voltadas tanto para o auto-conhecimento, quanto para o conhecimento das profissões no processo de orientação. Esta proposta corresponde a um dos objetivos do analista do comportamento que promoverá auto-conhecimento ao analisar funcionalmente com o adolescente, as variáveis das quais o comportamento de escolha profissional é função. Por outro lado, os modelos decisionais (Hilton, 1959; Hershenson e Roth, 1966; Gati, 1986; Gati, Shenhav e Givon, 1993) têm contribuído ao proporem a delimitação de um procedimento seqüencial para orientar o processo de tomada de decisão, categorizando e sugerindo passos a serem dados em direção a uma decisão efetiva. Estabelecendo um paralelo com a intervenção do analista do comportamento, este pode valer-se do treino de habilidades básicas, levando o orientando a avançar sucessivamente em sua escolha (modelagem) e analisando alternativas passo a passo, segundo alguns critérios selecionados rumo a uma decisão terminal.

\section{O que a Análise do Comportamento tem a oferecer à Orientação Profissional?}

Azrin e Besalel (1980) publicaram um programa de reabilitação vocacional fundamentado pela análise comportamental. O programa é voltado para pessoas desempregadas que buscam recolocar-se no mercado de trabalho e aponta vários pressupostos da orientação vocacional que podem nortear intervenções com outras populações. Segundo estes autores, a abordagem comportamental ao aconselhamento vocacional tem várias características que a diferencia de outras abordagens: 1) as estratégias são prioritariamente orientadas para o resultado: encontrar emprego (ou, no caso, decidir-se por uma profissão), 2) a intervenção enfatiza a aprendizagem como determinante do comportamento ao invés das habilidades ou predisposições inatas, sendo que um treinamento adequado pode levar o indivíduo ao alcance das habilidades necessárias para uma profissão, e 3) os conselheiros fazem uso do reforçamento de múltiplas fontes para obter mudanças comportamentais e um aumento na motivação para seguir o processo de busca de informação.

Desta forma, considera-se que Análise do Comportamento possa contribuir com a 
prática de orientação profissional a medida em que estabelece um referencial teórico que coloca a escolha profissional em uma perspectiva abrangente, tornando o orientando sujeito ativo em sua escolha. Além disso, dispõe de um conjunto de procedimentos de intervenção que dão conta de aspectos centrais da tomada de decisão. Estas contribuições parecem suficientemente amplas para abarcar o conjunto de variáveis envolvidas na escolha profissional e fornecer ao adolescente o apoio necessário para a superação de seus conflitos rumo a uma escolha consciente, baseada em suas possibilidades concretas.

\section{Objetivo}

O objetivo deste trabalho foi avaliar uma experiência de Orientação Profissional segundo o enfoque da Análise do Comportamento através da verificação de mudanças ocorridas no comportamento de escolha profissional de adolescentes que foram submetidos aos Programa de Orientação. Hipotetizou-se que uma intervenção sistematizada e focalizada nesta problemática e em seus determinantes poderia levar a ocorrência de progressos significativos no comportamento de tais adolescentes em relação aos indicadores da escolha profissional e assim demonstrar a efetividade da aplicação do enfoque comportamental à Orientação Profissional, apontando um caminho para o aprimoramento da presente proposta em investigações futuras.

\section{Método}

Sujeitos: Participaram da intervenção 10 adolescentes, sendo 06 femininos e 04 masculinos com idades entre 15 e 19 anos, todos cursando o Ensino Médio. Três grupos foram atendidos concomitantemente, e os resultados dos 10 sujeitos que completaram integralmente o processo de intervenção foram agrupados para fins de análise.
Local: Os atendimentos foram realizados nas dependências da Clínica Psicológica da Universidade Estadual de Londrina.

\section{Procedimento:}

O procedimento constou de três fases:

$1^{\text {a }}$ Fase: Pré-Teste: Antes do início dos atendimentos foi feita uma caracterização dos sujeitos e o levantamento preliminar da situação atual dos adolescentes em relação a escolha da profissão através de um instrumento contendo questões referentes a indicadores relevantes da escolha profissional (adaptado de Vasconcellos, Oliveira \& Carvalho, 1976).

$2^{\text {a }}$ Fase: Intervenção: O programa de Orientação Profissional constou de nove sessões estruturadas para discussão da problemática vocacional dos adolescentes, os quais receberam atendimento em grupo. As sessões foram focalizadas no desenvolvimento do processo de auto-conhecimento e conhecimento das profissões. Cada grupo atendido constou de sessões semanais com duração de duas horas, sob a coordenação de dois orientadores e tiveram a presença de um observador, que permaneceu na sala para registro dos dados.

O Programa de intervenção foi estruturado da seguinte maneira: as sessões de um a três deram ênfase para o trabalho de autoconhecimento, visando promover discriminação de habilidades, aptidões, interesses, aspirações, perspectivas pessoais e sociais relacionadas com as condições de vida de cada adolescente. As sessões de quatro a seis estão voltadas para o trabalho de fornecimento de informação sobre as profissões visando aumentar a consciência das contingências relacionadas com: carreiras, cursos de nível técnico e superior, vestibulares e mercado de trabalho. Buscou-se ainda desenvolver habilidades básicas de busca de informações concretas e atualizadas sobre uma dada profissão. Por último, as sessões de sete a nove visaram a integração das informações obtidas até então e fomento à tomada de decisão efetiva. 
$3^{\text {a }}$ Fase: Pós-Teste: Para que os dados fossem comparados, ao final das nove sessões, os adolescentes foram novamente submetidos ao mesmo instrumento utilizado no pré-teste. Os adolescentes esponderam ainda a um questionário de Auto-avaliação e de Avaliação do Programa de Orientação.

\section{Resultados}

Os resultados apresentados a seguir referem-se ao agrupamento comparativo dos dados provenientes de três grupos de intervenção que foram atendidos concomitantemente. Como houveram algumas desistências nos grupos, os dez sujeitos que finalizaram os atendimentos foram agrupados para fins de análise, uma vez que o mesmo procedimento foi mantido para os três grupos de sujeitos.

No início, todos os adolescentes apresentaram dúvida entre três opções profissionais, ao passo que, ao final, 50\% considerou entre uma e duas profissões para escolha. Entre os que mantiveram três opções, alguns rearranjaram a ordem de prioridades e outros incluíram opções não antes consideradas.

A influência da opinião da família e de amigos foi minimizada ao final da intervenção, sua freqüência foi reduzida de um para zero; enquanto que a percepção sobre características pessoais incompatíveis com certas profissões apresentou aumento de dois para quatro. Verificou-se que a probabilidade de empregar-se na profissão foi um fator indicado duas vezes no início e três vezes no pós-teste. As vantagens financeiras oferecidas foram citadas cinco vezes ao final do programa e três vezes no pré-teste. O status social atribuído às profissões passou a exercer influência na escolha profissional, tendo sido indicado uma vez no pós-teste. Por outro lado, somente um adolescente indicou o fato de "dispor de informações apenas sobre uma dada profissão" como influente na escolha, após ser submetido ao Programa. Os fatores "gosto pela profissão"; "habilidades e aptidões"; "contato prévio (com a profissão)" e "orientação profissional" não se alteraram, comparando-se o pré e o pós-teste.

Ao final do processo, seis adolescentes consideraram-se bem informados acerca de uma profissão favorita. Outros quatro adolescentes passaram a se considerar bem informados sobre suas segundas e terceiras opções de escolha profissional, enquanto que no início da intervenção, para qualquer das opções consideradas, o nível de informação era muito baixo, variando de zero a dois.

No pós-teste, houve uma diminuição da influência de fatores que dificultavam a tomada de decisão em relação à profissão para todos os participantes. Entretanto, 50\% das respostas indicaram que os adolescentes ainda sentiam-se atraídos por diferentes carreiras. O fator "pouco conhecimento sobre as profissões", indicado com alta freqüência no pré-teste, deixou de ser relatado pelos adolescentes após a intervenção. Apenas um participante indicou que tinha pouco conhecimento sobre os cursos no pós-teste, enquanto que três o indicaram no início. Os fatores "dificuldade para estudar fora da cidade"; "falta de base para o curso"e "falta de método adequado de estudo", indicados no início não foram citados no pós-teste como fatores que dificultam a decisão.

Quanto aos sentimentos descritos pelos adolescentes no processo de decisão, verifica-se um aumento dos relatos de experiências subjetivas no sentido "segurança", considerando-se um continuum insegurança-segurança. No pré-teste, nenhum adolescente considerou-se "inteiramente seguro", em contraposição a dois que assim se descreveram ao final do processo de Orientação Profissional. A indicação de "sinto-me inseguro" ocorreu cinco vezes no pré-teste e apenas duas vezes ao final do programa. Entretanto, quatro dos adolescentes não descreveram mudanças nos 
sentimentos de segurança, comparando-se o pré e pós-teste.

Observa-se que, ao final do processo de orientação, quatro dos dez adolescentes estavam decididos quanto à profissão, o que fora indicado por apenas um deles no préteste; quatro consideraram-se "quase decididos" (três o indicaram no pré-teste) e outros dois localizavam-se entre "indecisos" (três indicaram esse fator no início) ou "com dificuldade" para efetivar uma escolha, tendo sido indicado duas vezes no pré-teste e duas vezes no final do programa.

\section{Discussão}

A comparação do pré e pós-teste sugere que a prática de Orientação Profissional sob enfoque da Análise do Comportamento parece se constituir numa forma promissora de intervenção em aconselhamento clínico.

Embora uma das estratégias de intervenção consistisse na promoção de aumento na variabilidade de opções e critérios de escolha, o efeito, ao final do processo de orientação, foi uma restrição do número de opções entre as quais os adolescentes apresentavam dúvida. Isto sugere que o processo de Orientação Profissional foi eficaz na modelagem de comportamentos relacionados à tomada de decisão. Os adolescentes parecem ter eliminado algumas opções de profissões que, inicialmente consideravam interessantes, ao receberem mais informações sobre diversas profissões. Investigar o processo individual dos adolescentes que se mantiveram em dúvida entre três opções profissionais, ou seja, que não apresentaram mudança com o curso do processo, poderia lançar luz sobre quais estratégias de intervenção mereceriam ser acrescentadas ou removidas em aconselhamentos futuros.

Verificou-se, após a orientação, que a opinião da família e dos amigos deixou de exercer influência marcante sobre a escolha dos adolescentes. Em contrapartida, o status social atribuído às profissões, as possibilidades de emprego e vantagens financeiras que, antes não exerciam influência sobre os critérios de escolha, passaram a ser consideradas. Talvez isso se deva ao fornecimento de informações sobre as profissões e à aproximação do orientando às contingências relacionadas a uma dada carreira, diminuindo expectativas irreais. Essa interpretação parece ser corroborada por uma freqüência menor de apontamentos, no pós-teste, do fator "dispor de informações apenas sobre uma profissão" como influente na escolha. Um número maior de adolescentes foi capaz de identificar "profissões incompatíveis com suas habilidades", como um fator que influenciou a exclusão de opções, o que sugere um aumento do auto-conhecimento e do conhecimento das características das profissões. De fato, o número de adolescentes que se considerou bem informado sobre as opções profissionais entre as quais estavam em dúvida aumentou sensivelmente no pós-teste.

A Orientação Profissional não foi indicada antes, nem depois do processo de aconselhamento como fator que estivesse influenciando a escolha da profissão. Isso parece indicar que o processo de aconselhamento não teve caráter coercitivo, embora fosse diretivo. Aparentemente, a orientação apenas esteve relacionada com a diminuição da influência de outros fatores coercitivos. Já o "contato prévio" com as profissões, o gosto por elas e as "habilidades e aptidões" foram fatores indicados como influentes na escolha, tanto antes quanto ao final da Orientação Profissional.

Os conselhos parecem ter sido menos indicados como influentes na escolha, ao final do processo, pelo fato de os adolescentes terem sido encorajados a buscarem de modo autônomo e direto as informações relevantes sobre as profissões. Isso parece ser corroborado pela indicação dos adolescentes 
que afirmaram estar mais informados, sobre a opção profissional de maior interesse, (se primeira, segunda ou terceira) proporcionalmente, o que sugere um processo ativo de busca de informação relevante.

A intervenção pareceu diminuir a quantidade de fatores que dificultavam a decisão profissional. Embora ainda houvesse dúvidas no pós-teste quanto ao mercado de trabalho e os cursos, pode-se notar que o pouco conhecimento das profissões, freqüentemente apontado no pré-teste, deixou de ser um fator que dificultava a decisão ao final da orientação. Verifica-se que 50\% dos adolescentes ainda sentiam-se atraído por diferentes carreiras ao final da orientação, porém, a maior parte dos relatos subjetivos dos sentimentos vivenciados pareceu migrar de "inseguros" para "seguros" e "inteiramente seguros".

Ao término do processo de orientação, quatro, dos dez adolescentes consideraram-se decididos quanto a profissão e outros dois afirmaram estar "quase decididos". A orientação pareceu auxiliar mais àqueles adolescentes que estavam indecisos, mas já dispunham de algumas opções, do que àqueles que ainda não tinham selecionado as opções a serem consideradas. Esse dado sugere que estratégias diferentes devam ser empregadas para ajudar adolescentes que ainda não dispõem de opções para escolha profissional, ao passo que, para aqueles que já dispõem dessas opções, o programa sistematizado demonstrou ser promissor.

Quanto a este resultado, deve-se considerar ainda que tais adolescentes não participaram do mesmo grupo de orientação. Sendo assim, mesmo sob influência das mesmas estratégias clínicas, o resultado mais ou menos próximo de uma tomada de decisão segura, também deve ser atribuído a forma de condução dos grupos por diferentes terapeutas. Sabe-se que a forma como as estratégias são empregadas e as características pessoais mais ou menos facilitadoras dos terapeutas são variáveis relevantes a serem consideradas como influentes, principalmente em se tratando de adolescentes.

Finalmente, deve-se considerar a necessidade de aprimoramento do instrumento empregado no pré e pós-teste, pois algumas informações relevantes sobre o processo individual pareceram se dispersar nas categorias estabelecidas, dificultando a confrontação dos dados para fins de comparação, enquanto outras questões foram muito amplas para que os adolescentes pudessem expressar de forma objetiva os ganhos obtidos com o processo de orientação.

Além disso, as estratégias de intervenção eficazes no desenvolvimento da habilidade de selecionar opções profissionais prévias merecem ser propostas e testadas. Afinal, os dados sugerem que essa habilidade se traduz em um passo inicial, sem a qual o repertório de tomada de decisão torna-se inefetivo, fazendo com que a tarefa de escolha profissional seja custosa e arriscada para o adolescente.

\section{CONCLUSÃO}

O presente estudo, apesar de constituir-se numa avaliação inicial de uma experiência integrando Análise do Comportamento e Orientação Profissional, sugere que uma intervenção sistematizada e focalizada na problemática da escolha profissional e em seus determinantes pode levar a ocorrência de progressos significativos no comportamento de adolescentes em relação aos indicadores da escolha profissional.

Partindo-se dos conhecimentos prévios quanto a importância de se trabalhar com auto-conhecimento e conhecimento das profissões (Lucchiari, 1993; Billups e Peterson, 1994; Neiva, 1995; Macedo, 1998) foi possível avançar não apenas sobre a proposição de estratégias adequadas aos objetivos, mas 
sobre a forma como tais estratégias foram implementadas no processo de tomada de decisão.

As estratégias de intervenção visaram principalmente o aumento na variabilidade comportamental dos adolescentes quanto ao contato com o contexto das profissões. Partia-se do pressuposto que aumentando as informações quanto a critérios relevantes de escolha (aqueles relativos a características pessoais e das profissões), os adolescentes fossem mais capazes de restringir suas opções com base na seleção de seus próprios critérios (Gati, 1986; Gati, Shenhav e Givon, 1993).

A escolha de critérios de seleção/ exclusão de opções é muito importante no processo de tomada de decisão, pois sabe-se que a integração do conhecimento sobre si mesmo e sobre profissões não leva mais a uma combinação única homem/profissão (Macedo, 1998). Desta forma, os adolescentes foram levados a explorar as profissões através de material atualizado, que possibilitasse a eles acesso a informações específicas sobre as mudanças emergentes dos cursos e mercado de trabalho. E a conhecer não só seus atuais interesses e habilidades, mas também suas potencialidades, as quais podem vir a ser desenvolvidas mediante um bom treinamento técnico, para atenderem a exigências profissional que sejam de interesse pessoal.

Além disso, a presente avaliação permitiu identificar no repertório dos adolescentes, aspectos comportamentais considerados requisitos básicos para que uma escolha efetiva se torne mais provável. Por exemplo, a diferença observada entre os adolescentes que trouxeram opções prévias para a Orientação e os que não dispunham delas. Os que haviam selecionado previamente algumas opções a serem consideradas responderam melhor às estratégias utilizadas neste modelo de intervenção. Estudos ulteriores poderão explorar mais este aspecto, propondo e testando formas de intervenção que fomentem o desenvolvimento desses requisitos básicos, e auxiliem tais adolescentes, da mesma forma, no processo de decidir seu futuro profissional.

No momento, este estudo nos permite concluir que, assim como no modelo de Reabilitação Profissional proposto por Azrin e Besalel (1980), os princípios comportamentais mostraram-se úteis para o desenvolvimento de programas estruturados de Orientação Profissional com adolescentes. Desta forma, a Análise do Comportamento parece oferecer uma base conceitual promissora para que os programas de Orientação Profissional possam fundamentar-se numa análise cuidadosa da dificuldade de escolha de cada adolescente, oferecendo uma forma de auxilio efetivo neste processo, qualquer que seja seu repertório de entrada quanto à tomada de decisão.

\section{REFERÊNCIAS BIBLIOGRÁFICAS}

AZRIN, N.H. \& Besalel, V.A. (1980). Job Club Counselor's Manual: A behavioral approach to vocational counseling. Austin: Pro-ed.

BILLUPS, A. \& Peterson, G.W. (1994). The Appreciation of Career Literature in Adolescents. The Career Development Quarterly. 42, 229-237.

BOHOSLAVSKY, R. (1977). Orientação vocacional: A estratégia clínica. São Paulo: Martins Fontes.

GATI, I. (1986). Making career decision - A sequential elimination approach. Journal of Counseling Psychology, 33, 408-417.

GATI, I., Shenhav, M. \& Givon, M. (1993). Process involved in carrer' preferences and compromises. Journal of Counseling Psychology. 40 (1), 53-64.

HERSHENSON, D. S. \& Roth, R. M. (1966). A decisional process model of vocational development. Journal of Couseling Psychology,13 (3), 368-370. 
HILTON, T. L. (1959). Career decisionmaking. Journal of Couseling Psychology, 6, 291-298.

HOLLAND, J. (1971). Técnica de la elección vocacional: tipos de personalidad y modelos ambientales. México: Trillas.

LUCCHIARI, D.H.P.S. (Org). (1993). Pensando e Vivendo a Orientação Profissional. São Paulo: Summus.

MACEDO, R. B. M. (1998). Seu diploma, sua prancha: como escolher a profissão e surfar no mercado de trabalho. São Paulo: Saraiva.
NEIVA, K. M. C. (1995). Entendendo a Orientação Profissional. São Paulo: Paulus.

ROE, A. (1972). Psicologia de las profesiones. Madri: Marova.

SKINNER, B. F. (1974). Sobre o Behaviorismo. São Paulo: Cultrix.

SKINNER, B. F. (1989). Ciência e Comportamento Humano. São Paulo: Martins Fontes.

VASCONCELLOS, M. J .E., Oliveira, A. L. Q. \& Carvalho, M. A. V. (1976). Curso de Informação Profissional, Belo Horizonte: Vigília, Rio de Janeiro: FENAME. 